\title{
Las injusticias informativas como injusticias epistémicas
}

\author{
Informational injustices as epistemic injusticies
}

\author{
Ariel Morán \\ Professor da Faculdade de Filosofia e Letras na \\ Universidad Nacional Autónoma de México - UNAM. \\ E-mail: a.moran@ comunidad.unam.mx
}

\section{Resumen}

En este trabajo se define lo que es una injusticia informativa, a la luz de las investigaciones sobre injusticias epistémicas, específicamente en dos de sus modalidades: las injusticias testimoniales y las injusticias hermenéuticas. Además de esto, se tratan algunas de las implicaciones fundamentales que surgen para el trabajo de archivistas y biblbiotecarios.

Palabras clave: Injusticias informativas. Injusticias epistémicas. Asimetrías de la información. Malinformación. Desinformación.

\section{Resumo}

Este trabalho define o que é uma injustiça informativa, à luz de pesquisas sobre injustiças epistêmicas, especificamente em duas de suas modalidades: injustiças testemunhais e injustiças hermenêuticas. Além disso, algumas das implicações fundamentais são desenvolvidas para o trabalho dos arquivistas e biblibrários.

Palavras-chave: Injustiças informativas. Injustiças epistêmicas. Assimetrias de informação. Malinformação. Desinformação.

\begin{abstract}
In this work defines what is an informative injustice, under the spotlights of research on epistemic injustices, specifically in two of its modalities: testimonial injustices and hermeneutical injustices. In addition to this, some of the implications that arise for the work of archivists and librarians are discussed.
\end{abstract}

Keywords: Informative injustices. Epistemic injustices. Asymmetries of information. Misinformation. Disinformation. 


\section{La injusticia informativa como una injusticia epistémica testimonial}

Una injusticia epistémica se genera cuando se quebranta una facultad esencial para la dignidad humana que es la de ser sujetos de conocimiento. Este tipo de injusticias representan estructuras de poder desigual y prejuicios sociales, además de que entrañan fuertes problemas éticos, los cuales llegan a adoptar proporciones de opresión contra determinadas comunidades minoritarias que son ignoradas del espectro del desarrollo de conocimiento, tanto en procesos de creación como de compartición.

Existen dos tipos básicos de injusticias epistémicas: injusticias testimoniales (vinculadas con la creación de conocimiento) e injusticias hermenéuticas (relacionadas con la compartición e interpretación de ese conocimiento). Una injusticia testimonial es una injusticia dirigida a los emisores de información; una injusticia hermenéutica es una injusticia infligida sobre los receptores de información. Las injusticias testimoniales se refieren a la imposibilidad a la que se ven sometidos ciertos sectores marginados cuando se impide que su voz y experiencia puedan ser consideradas insumos de conocimiento (por ejemplo, la desacreditación de los llamados "archivos vivos", que contienen testimonios de víctimas de violaciones a derechos humanos). Las injusticias hermenéuticas hacen alusión al bloqueo que sufren algunas comunidades para recibir información y conocimiento, por lo que su interpretación del mundo se ve sesgada (la información falsa o la censura son un tipo de injusticia hermenéutica).

En este sentido, una injusticia informativa es una injusticia epistémica en tanto se obstaculizan determinadas prácticas vinculadas con el acto informativo, o cuando se interfiere con la capacidad de distribuir y compartir ciertos bienes epistémicos, específicamente bienes informativos (o bienes educativos vinculados con algunos sistemas de información documental), por lo que se ven afectadas aquellas capacidades según la condición de ser sujetos cognoscentes y potenciales partícipes de una comprensión socialmente compartida (para conformar así lo que Miranda Fricker llama un poder indentitario). Esta investigadora británica aduce que, al lesionar el potencial de alguien, en tanto portador de conocimiento o informante, "el principal daño que se padece al sufrir este agravio es intrínsecamente una injusticia” (FRICKER, 2017, p. 23). Impedir el desarrollo de prácticas cognoscitivas es, en sí mismo, una injusticia, dado que "el conocimiento 
está en todo el organismo, o mejor, lo que conozco, y en la medida del conocimiento, hace parte de lo 'mío"' (GONZÁLEZ, 2015, p. 80).

Un ejemplo de esto se da cuando se impide que algunas comunidades se empoderen haciendo uso del acceso a las TIC (vistas como herramientas de liberación) por razones de prejuicios identitarios. Estos instrumentos están ceñidos por lo regular a ciertas comunidades de élite (para sostener relaciones de poder), como las científicas o las gubernamentales, ya que se asume, desde un discurso hegemónico, que son las únicas capacitadas para seleccionar, discriminar y jerarquizar propiamente el material informativo. (LUCAS GALLEGO, 2017, p. 319). Otro ejemplo se presenta a través de una forma exacerbada de la injusticia testimonial, la llamada injusticia testimonial anticipada, la cual se genera "antes de que haya un potencial intercambio de información; se adelanta a cualquier intercambio semejante”. Este tipo de injusticias se presentan sobre todo en los archivos gubernamentales que resguardan algunas colecciones documentales vinculadas con acontecimientos en los que se suscitaron flagrantes violaciones a los derechos humanos de personas o grupos específicos. Lo que ocurre es que se "sufre ya un déficit tan prejuicioso que no se solicita nunca su testimonio potencial; de manera que el prejuicio identitario que merma de antemano su credibilidad acalla al hablante" (FRICKER, 2017, p. 213).

La contribución hacia ciertos procesos comunicativos por parte de las tecnologías digitales es innegable. Si bien muchos procesos "pueden hacerse más efectivas a través del apoyo a las instituciones que ayudan a divulgar la información y a mejorar las oportunidades para las discusiones que trascienden las fronteras", también debe reconocerse que "la pluralidad de las fuentes enriquece el alcance de la democracia global a la luz de esta perspectiva. Muchas instituciones tienen un papel aquí" (SEN, 2010b, p. 441), incluidas las bibliotecas y los archivos. No obstante, la dinámica de muchos de los sistemas de información actuales parece estar en clara sintonía con algunas de las causas estructurales de muchas injusticias en el mundo globalizado, ya que lo que se hace es marginalizar o invisibilizar ideas que no convergen con el canon: "las redes de información de los medios de comunicación globales y de la cibertecnología” son quienes "determinan quién está incluido en los circuitos de poder de la comunicación y quién no" (FRASER, 2008, p. 86).

Esto propicia la gestación de prejuicios identitarios, mismos que remiten a la credibilidad que pueden llegar a tener los agentes durante el acto informativo (ya sea por exceso o déficit de 
credibilidad), por ejemplo, si se es un académico reputado o sólo alguien de la masa social que “opina" (la contraposición entre la epistéme y la dóxa). Esta suele ser la principal expresión de una injusticia testimonial. El testimonio cumple una función epistémica muy importante en cuanto a la adquisición y distribución social de la información y del conocimiento, aunque resulte siempre discutible el tema de la credibilidad del testimonio y del testimoniante (Cfr. GONZÁLEZ DE REQUENA FARRÉ, 2015, p. 53-54). Tanto el exceso como el déficit de credibilidad son determinadas por cargas epistémicas (experiencias individuales y colectivas) y hasta éticas.

En la actualidad, por extraño que pueda resultar en su enunciación, el acto informativo (que entraña al testimonio) no está definido sólo por la información, sino por una especie de representación performativa alrededor, que involucra estrategias que remarcan la construcción dialógica y polifónica de la testificación. Esto llega a tal grado que, en muchas ocasiones, el acto informativo está determinado en menor medida por la información, y más por el prejuicio o la emotividad: "el prejuicio tenderá a exagerar o devaluar de manera subrepticia la credibilidad otorgada al hablante [...] hasta el extremo de que el prejuicio del oyente le lleve a prescindir de un dato de conocimiento" (FRICKER, 2017, p. 42). La atribución de credibilidad, por lo general, cuando es excesiva, suele ser conveniente, y cuando es deficitaria suele ser desventajosa. Sin embargo, tal situación se da de esta manera, pues existen escenarios en los que el exceso no trae necesariamente ventajas y en los que el déficit puede ser benéfico (de la misma manera en que Amartya Sen no consideró que la exclusión de información sea algo puramente malo, ni que la inclusión de información se constituya siempre como un elemento favorecedor para las libertades sociales). Debe comprenderse que se trata de un juego de relaciones de poder y de contrapesos, y que en muchas ocasiones se suministra información emergente o fáctica para inducir a que las personas procedan de cierta manera. En otros casos, ocurre el efecto contrario, pues se escatiman algunos datos para evitar que actúen. Amartya Sen, criticó algunos de los enfoques de la filosofía política liberal que abordaban el tema de la información y la justicia social (como el de John Rawls o Robert Nozick) y propuso dos criterios para la evaluación de los niveles de justicia en una sociedad libertaria: la información incluida y la información excluida (SEN, 2010a, p. 78-79).

Antes del asentamiento de los Estados benefactores, se tenía en alta consideración, por parte de los sistemas de información gubernamental, el principio de utilidad para considerar si era adecuado incluir o excluir información, dependiendo del caso (si un lote de información no era útil 
para un grupo en particular podría excluirse, pero si ciertos documentos eran por demás útiles era preciso incluirlos en los sistemas de suministro de información). En síntesis, la información estaba en función de la expansión de las capacidades individuales a partir del principio de utilidad y competencia. Pese a que este principio era eficaz para percibir los resultados del trabajo de las instituciones, resultaba por demás reduccionista equiparar utilidad con bienestar (ya que se solían excluir aquellas libertades y derechos fundamentales que no prestaban una "utilidad", como la libertad de expresión o el derecho universal a la información). Para el economista bengalí, es la justicia social la que debe encargase de procurar, precisamente, el "bien-estar", y no sólo la mera utilidad. A diferencia de Nozick o Rawls, Sen consideró que la información debe proporcionar un bienestar colectivo y no sólo un corpus de libertades individuales, puesto que esto puede acarrear aventajamientos asimétricos entre los mismos individuos. El bienestar, en un sentido económicosocial, filosófico, y hasta religioso, conlleva la diversidad y la heterogeneidad, tanto personal, como de nuestro entorno y del clima social. En este sentido, el derecho a la información debe constituir una vía para bosquejar y alcanzar una vida que merezca ser vivida, una vida real sin privación de bienes primarios, libertades básicas y con plenitud de capacidad para trazar los propios caminos para desarrollarse.

\section{La injusticia informativa como una injusticia epistémica hermenéutica}

Una injusticia hermenéutica se produce cuando existe una brecha cognoscitiva en los recursos de interpretación colectivos que posiciona a una persona o a un grupo en una desventaja en lo relativo a la comprensión de sus experiencias sociales. Por tanto, será siempre importante que las herramientas hermenéuticas de que disponen las personas para dar sentido a las cosas estén debidamente informadas, sin ningún tipo de desigualdad injusta. Judith Shklar enfatiza que "a la hora de hacer juicios bajo condiciones de información más que incompleta la mayoría de nosotros malinterpreta la evidencia disponible" (SHKLAR, 2013, p. 64). En los fondos documentales existe mucha información incompleta o sesgada ideológicamente, que constituye al mismo tiempo una serie de injusticias testimoniales y hermenéuticas, ya que no se permite que ciertas voces del pasado se expresen ni que los ciudadanos actuales las interpreten. Debe tenerse presente que los archivos constituyen socialmente los límites y formas de la reactivación de la memoria (como relaciones y validadas entre los discursos del pasado y del presente), y de su conservación (en tanto documentos 
valorados que circulan para poder ser utilizados de acuerdo con ciertos fines) (FOUCAULT, 1983, p. 100). En el caso de los archivos, José Antonio González alude que:

[...] las modalidades de testimonio que atestiguaron las formas de violencia política y el terrorismo de Estado en Latinoamérica, tienen la particularidad de haberse concretado en un abundante corpus de literatura testimonial y no sólo en los registros judiciales, en los informes oficiales o en los archivos de organizaciones vinculadas a la defensa de los derechos humanos. En efecto, existe todo un género de literatura del testimonio, que, a su vez, ha generado una intensa reflexión crítica sobre las formas, e incluso los métodos, de trabajo de la escritura testimonial en el ámbito de los estudios culturales y la crítica literaria. Sin embargo, a pesar de esta relativa autoconciencia literaria y académica del género del testimonio, los usos y funciones de la literatura testimonial latinoamericana han ido modificándose con los cambios en los escenarios políticos como consecuencia de los procesos de transición democrática y de reconciliación (GONZÁLEZ DE REQUENA FARRÉ, 2015, p. 60).

No obstante, pese a todo esto, debe tenerse muy presente que "el empleo estratégico del testimonio, al servicio de la representación ideológica, implicó la codificación de un cierto libreto de convenciones de género y técnicas de escritura que terminaron enmarcando instrumentalmente los usos del testimonio" (GONZÁLEZ DE REQUENA FARRÉ, 2015, p. 60). Los archivistas no pueden formarse profesionalmente como agentes apocados que propicien y preserven este tipo de injusticias, guiadas por lo general por intereses políticos:

La transformación del archivista tradicional en un nuevo profesional en el manejo de la información generada en las organizaciones son, en la actualidad, los elementos que deberán considerarse para renovar las añejas y polvorientas estructuras archivísticas. La transición del archivista tradicional, en principio, suena fácil; sin embargo, en la práctica se ha enfrentado a serias controversias y ha tenido que atravesar por un largo y lento proceso de evolución, para lograr ese paso, de los postulados tradicionales que le conferían la autoridad plena y única para custodiar el tesoro documental de las instituciones, a la participación activa en el diseño e instrumentación de políticas de gestión de la información en las administraciones públicas y las empresas privadas (TÉLLEZ GONZÁLEZ Y GÓMEZ GALLARDO, 2012, p. 167).

La información que se resguarda en muchas instituciones públicas está emitida desde un contexto político e ideológico particular, por lo que muchas veces el documento - como medio que presta testimonio - preserva un discurso hegemónico que busca preservar relaciones de dominación. El hecho de que un documento provenga de un tiempo remoto no implica que éste no contenga en su confección algún sesgo o carga teórica. Tanto en su contenido como en su materialidad, el documento de archivo presta testimonio del contexto de su época. La formación crítica del archivista suele relegar este aspecto, ya que, por lo general, se suele aceptar sin mucha renuencia el testimonio de aquellas voces que nos hablan desde un pasado remoto o no tan cercano, 
ya que su "conservación" se asocia con "antigüedad", por lo que éstas se asumen con fuentes confiables sólo por ser antiguas (una falacia del tipo argumentum ad antiquitatem):

Es probable que sea así con el conocimiento de asuntos espacial y temporalmente lejanos al sujeto, aunque aquí vale la pena recordar la perogrullada de que todos poseemos información acerca del pasado (y dejando de lado el caso especial de nuestros propios pasados), que es justamente aceptada como conocimiento, aunque las proposiciones que emanen de ella no puedan sustentarse con razones lógicamente adecuadas, sino en el hecho "externo" de que hemos adquirido la información a partir de fuentes presumiblemente confiables que ahora no solemos recordar (WILLIAMS, 2017, p. 73).

Aundado a lo anterior, Byung-Chul Han aduce que la información no posee por sí misma un "aroma", o sea que su naturaleza no refiere a un factum determinado, porque precisamente la información adquiere relevancia cuando un agente intencional la valora y la interpreta, afectando su visión del mundo:

Las informaciones no tienen aroma. En eso se diferencian de la historia [...] la información no se relaciona con la historia como la simulación siempre perfecta del original o del origen. En realidad, la información representa un nuevo paradigma. En su interior habita otra temporalidad muy diferente. Es una manifestación del tiempo atomizado (HAN, 2016a, p. 36).

Una injusticia hermenéutica no sólo se genera cuando se obstaculiza la circulación de información, sino cuando se avasalla y se le abruma a las personas con el torrente inasible de los flujos informativos. Este maremágnum se vuelve incomprensible debido a que esa ingente cuantía de información es inconmensurable. Si la información no está diseminada a través de categorías de clasificación, según una lógica epistémica, las personas no pueden asimilarla. Mucha de esa información se vuelve banal, pues aunque es vasta ésta trilla en la repetición temática de sus fuentes: "La proliferación de lo igual se hace pasar por crecimiento. Pero a partir de un determinado momento, la producción ya no es productiva, sino destructiva; la información ya no es informativa, sino deformadora; la comunicación ya no es comunicativa, sino meramente acumulativa" (HAN, 2017, p. 10). En este sentido, "de nada sirve guardar archivos con conocimientos que no van a ser compartidos con nuestros congéneres. No tiene objeto mantener información que no va a enriquecer la vida" (RESTREPO, 1994, p. 140). La información como materia prima del conocimiento, debe encaminarnos procesos de bien-estar, ya que como precisó don Fernando González, el filósofo de Otraparte: “Conocer es convivir hasta unificarse con algo" (GONZÁLEZ, 2015, p. 80). Entonces, para que el conocimiento establezca dialogicidad es necesario que la información no adolezca de su dimensión de alteridad. 
Además de lo anterior, una injusticia informativa no sólo refiere a la obstaculización de la distribución de información, sino al desarrollo de otras prácticas informativas — como la distinción entre la información auténtica y la falsa - ya que de otra forma sería conceptuada, meramente, como una injusticia distributiva en vez de una injusticia epistémica. Para Rawls, por ejemplo, una de las implicaciones en la falta de circulación de la información es la ruptura de los pactos sociales. Este teórico adujo que una persona no está obligada a cumplir su promesa (o sea, el contrato social) "si le fue negada con dolo una información pertinente", ya que "la racionalidad de la elección de una persona no depende de cuánto sabe, sino sólo de lo bien que razone a partir de la información de que disponga, por incompleta que sea" (RAWLS, 2014, p. 360). Sin embargo, ante la falta de información pertinente, el grueso de personas actúa con esa incompletitud informativa, "actuamos así todo el tiempo, sin información completa, porque no nos queda otra opción” (SHKLAR, 2013, p. 37).

\section{Las asimetrías informativas}

Así como en los ámbitos del derecho, la ecología o en la salud pública, la información cobra una relevancia sustancial y estratégica, en otras áreas también influyen los fenómenos informativos, pues los estudios de la información son:

Un área que afecta desde los alimentos que comemos, nuestro entretenimiento, el tratamiento médico que recibimos, hasta los libros que leemos, las tecnologías que usamos, las escuelas, bibliotecas y universidades que conforman la infraestructura de primera línea de nuestros sistemas educativos y el tipo de empleo, estilos de vida e información básica a la que tenemos acceso (CORRIGAN, 2007, p. 212).

Además de esto, hoy más que nunca, está área “está teniendo un profundo impacto en la economía del conocimiento y es probablemente el área más importante de la política pública a la que la población en general sigue siendo en gran parte ajena” (CORRIGAN, 2007, p. 212).

Existen muchas explicaciones para fenómenos tales como la pobreza o la lucha de clases en la sociedad postindustrial, pero hay una condición que puede explicar muchas de las situaciones de desigualdad que históricamente han socavado la capacidad de acción y de desarrollo de las personas: la denominada "asimetría de la información” (BARRY, 2005, p. 89). Se hace imperioso precisar, antes que otra cosa, que el fenómeno de la asimetría de la información entraña un 
concepto utilizado comúnmente en la economía política y en la economía financiera especulativa, ya que ilustra una situación potencial en la que un agente posee mayor información —o que al menos ésta es más ventajosa - respecto a otros agentes, partiendo del principio de maximización de la utilidad (MARWALA; HURWITZ, 2017, p. 63-64; COOLEY; NAM, 1998, p. 610-611). Así como en la pugna de los mercados "es fundamental para la posición libertaria que los consumidores deban tener información clara sobre la base de la cual tomar decisiones” (BARRY, 2001, p. 42), también se hace imprescindible para otros escenarios (laborales, familiares, sanitarios, electorales, habitacionales, culturales) contar con información oportuna y pertinaz, ya sea para determinaciones inmediatas o para planes futuros.

La información es un bien que ostenta una cualidad especial: es un bien primario que ayuda a concebir y valorar otros bienes primarios. Esto implica que la información fortalece no sólo la identidad individual y colectiva, sino que potencia las facultades intelectivas y volitivas para realizar elecciones de índole social (familiares, profesionales, laborales). Hans Blokland profundiza en este tema y señala que "las personas deben tener acceso a la información correcta, deben intercambiarla de una forma adecuada, tener una visión general de las variables, por lo general numerosas, pertenecientes al asunto en cuestión, y las personas deben comprender las relaciones complejas entre estas variables" (BLOKLAND, 2011, p. 75). Fricker reconoce que este intercambio no es equilibrado, ya que "la vida discursiva incorpora demasiados contrapesos", lo que implica que "las personas se equivocan en sus apreciaciones; cometemos errores, tenemos mala suerte y a veces tal vez se nos antoje que sabemos algo cuando en realidad no es así [...] a veces la gente engaña u oculta información deliberadamente a los demás porque le interesa hacerlo" (FRICKER, 2017, p. 114).

Algunas de las modalidades de las asimetrías informativas son: los riesgos morales, las selecciones adversas y la difusión de información falsa. Un riesgo moral es una situación en la que una persona incurre en determinadas acciones, más allá de su campo de responsabilidad, sabiendo muy bien que las consecuencias serán pagadas por otras personas. La corrupción, especialmente de los funcionarios del gobierno, es un tipo de riesgo moral (cuando se desvían recursos del erario, se asume que las filtraciones de dinero serán subsanadas con lo que aportan los contribuyentes). La selección adversa comprende una circunstancia en la cual los vendedores o proveedores poseen más información que los compradores, o viceversa, así que, en consecuencia, unos agentes 
preparan el mercado para su ventaja sobre los otros agentes. Ambas son formas de asimetría de la información pues la extensión del riesgo es más conocida por un agente que por otro, por lo que se limita la racionalidad de las decisiones del menos aventajado. En pocas palabras, ambos casos tratan los efectos de dos o más partes que tienen diferentes grados de información sobre un hecho o un objeto en particular. Otro ejemplo de esto se puede observar de manera asidua en la industria de los seguros: "muchas de las problemas característicos, relacionados con las limitaciones informativas (especialmente la información asimétrica), el papel de los bienes públicos, las economías de escala y otros impedimentos se aplican con particular énfasis a los mercados de seguros" (SEN, 2010b, p. 297). Existen algunas situaciones en las que se saca ventaja del ocultamiento de información, pero no siempre son las organizaciones las que lo hace, sino los usuarios. En efecto, aquellas personas consideradas con altos riesgos (ya sea por su edad, su tren de vida o estado de salud) tienden a comprar más seguros (o con mayor cobertura), muchas veces ocultando información a las empresas aseguradoras sobre su real condición.

La mayor parte de las asimetrías informativas cobran relevancia debido a los beneficios que surgen del engaño. Para Brian Barry, la "insuficiencia de información” que se genera con las asimetrías también reduce el grado de responsabilidad por las consecuencias de las decisiones que las personas toman en estados de incertidumbre. "Para elegir entre opciones de manera sensata, se necesita comprender la naturaleza de las opciones [...] es inmediatamente evidente que la capacidad de adquirir y manipular información, y el ocio para hacerlo, se distribuyen por procedimientos muy desiguales" (BARRY, 2005, p. 138). Las asimetrías informativas se producen por varias modalidades, y la gran mayoría de ellas no resultan ser tan funestas como en los casos aludidos anteriormente; son parte del juego de la vida cotidiana. En este sentido, por supuesto, existen "juegos sucios", resultado de relaciones de poder interpersonales que se alimentan de información privilegiada, que pueden llegar a ser datos sustraídos, ya sea a través del espionaje industrial o de violaciones a la protección de datos personales. Se trata de situaciones en la que el resultado que se persigue es que una de las partes esté mejor informada que otra.

Ahora bien, la falta de información, no sólo afecta a los ciudadanos por la decisión de los propios ciudadanos, sino que se perjudica a los ciudadanos a causa de las decisiones de las autoridades. La circulación de "información insuficiente" trae como consecuencia que los sujetos obligados (las autoridades) tomen "decisiones sobre la asignación de recursos sin tener a su 
disposición información adecuada [...] Deben lidiar con tantos problemas y tomar tantas decisiones sobre la base de información insuficiente que ya no pueden ver el bosque por los árboles" (BLOKLAND, 2011, p. 96). Un escenario más dañino que la información insuficiente es la información falsa, pues no sólo nos evita actuar, sino que nos estimula a actuar de forma errónea. La ruta deliberativa de un sujeto será inconsistente si está basada en información falsa.

En este mismo sentido, debe enfatizarse que las asimetrías informativas pueden ser el resultado de conceptos erróneos sobre algunos datos, malentendidos, redundancias, creencias falsas o, incluso, cargas teóricas divergentes entre dos horizontes (no sólo por su parcialidad), lo que afecta cómo se valora e interpreta un hecho determinado. Es aquí, precisamente, donde entra el papel de la biblioteca y los bibliotecarios. Dos personas pueden buscar toda la información disponible sobre un tema en un banco de datos o en un repositorio, y es posible que los resultados de la búsqueda sean similares, pero el procesamiento y análisis que hagan sobre esta misma información documental puede conducir a conclusiones muy diferentes. El asunto de la consistencia de la información trae a colación el problema de la intención plasmada en las acciones voluntarias de los agentes. De manera cotidiana, en contextos informales, las personas suelen referirse a la información falsa a través de muchos denominativos, sin una distinción ponderada. Si bien en muchos ámbitos parece no suscitarse un gran problema ante esta situación, en los escenarios académicos sí se requiere estudiar la naturaleza de la información falsa con una mayor precisión y hacer un examen conceptual hasta una aquiescencia más o menos generalizada, con el principal cometido de conseguir la multiplicidad de significados. Surge, pues, la necesidad de hacer una diferencia sopesada entre los conceptos "malinformación" (misinformation) y “desinformación” (disinformation). Algunas propuestas llegaron a considerar que la primera debía referirse a aquella información falsa que, a sabiendas de su condición de falsedad, se difundía con el fin de confundir o sacar alguna ventaja, y la segunda como aquella que se hace circular creyendo que es verdadera. Floridi justifica una proposición diferente:

[...] me sigue pareciendo mucho más correcto usar "malinformación" para referirse a la información semántica falsa (por ejemplo, Alicia piensa que Milán es la capital de Italia, pero está malinformada), y la "desinformación" a aquella que se difunde con el fin de engañar a su receptor (por ejemplo, Alicia sabe que la capital de Italia es Roma, pero ella le dice a Bob que se trata de Milán con el fin de desinformarlo). El prefijo mal- en este tipo de información incierta parece ir de la mano con el mal en el 'error', pero por supuesto todo esto es en gran medida un tema de convenciones y usos lingüísticos (FLORIDI, 2012, p. 215). 
En un inicio, el uso terminológico que proponía Fallis para describir a la información falsa era contrario al de Floridi, ya que consideraba que la malinformación debería hacer referencia a la información falsa que se transmite intencionalmente para engañar (no sólo en los negocios o la vida pública, sino en cualquier ámbito), y la desinformación es aquella que se comparte porque se piensa, erróneamente, que es verdadera (muchas personas creen que la capital de Australia es Sydney o Melbourne, cuando se trata, realmente, de Canberra; asimismo, se asume que la capital de Florida es Miami, en vez de Tallahassee). Aquel disentimiento en el uso de estas dos palabras residía en que para Fallis el prefijo mis- (mal-, en español) hace alusión a la "maldad" o a lo "malicioso" (al menos en su enunciación), y, por ende, la malinformación debe referirse al engaño intencional que se hace a través de información falsa. No obstante, como se señala en la cita, Floridi adujo que mis- efectivamente hace alusión a lo que está "mal”, pero no necesariamente en relación con lo "malvado". Él arguye que la sugerencia de Fallis circunscribe la cuestión de la información falsa a un problema moral. En realidad, en términos lógicos, decir que algo "está mal" tiene que ver más con un error o un defecto (que en los estudios de la información es un elemento siempre presente), incluso un malestar, pero no por fuerza un origen en el mal en sí. Cuando alguien expresa que padece un mal cardiaco, ese "mal" no tiene detrás la mala intención de alguien, sino un padecimiento que lo aqueja. En un sentido cotidiano, el "mal" tiene que ver con errores (con la condición de falibilidad del ser humano), por lo que no necesariamente debe existir un dilema ético derivado de una intención maliciosa. Cuando se dice que alguna una actividad estuvo mal ejecutada, que un estudiante respondió mal a una pregunta del examen, o que un mueble está mal acomodado, simplemente esto alude a un error de sentido o incomprensión, pero no a un problema ético.

Por otro lado, puede decirse que el problema de la desinformación se vincula, más bien, con el hecho de que el intercambio cotidiano de información no es del todo equilibrado, ya que "la vida discursiva incorpora demasiados contrapesos". Esto implica que: "En primer lugar, las personas se equivocan en sus apreciaciones; cometemos errores, tenemos mala suerte y a veces tal vez se nos antoje que sabemos algo cuando en realidad no es así. Y, en segundo lugar, a veces la gente engaña u oculta información deliberadamente a los demás porque le interesa hacerlo" (FRICKER, 2017, p. 114). 
A pesar de la practicidad de la propuesta de Fallis (que da primacía a la enunciación fonética mal- en relación con lo "malo"), mucha de la literatura que ha abordado este problema ha optado por retomar la propuesta de Floridi, sobre todo porque se considera que sus argumentos contemplan la complejidad de las muchas dimensiones que se entraman con el fenómeno de la información falsa. Por supuesto, la aproximación moral es una posibilidad entre varias. Por ejemplo, si un bibliotecario referencista no atendió con prestancia y cuidado los requerimientos de información de un usuario, cabe la posibilidad de que lo haya hecho con una mala intención o por desidia (lo que atañería a la ética, por una omisión en su responsabilidad profesional); pero la mayoría de las ocasiones, la baja satisfacción de los usuarios en este servicio obedece a otras circunstancias: errores en la comunicación, falta de capacitación, obsolescencia de los materiales, entre otras causas.

Como ocurre en los juegos del lenguaje a los que aducía Ludwig Wittgenstein, el sentido de una palabra está determinado por el uso, y, dado que la mayor parte de la literatura sobre este tema ha preferido recurrir a la propuesta del uso terminológico de Floridi, en este trabajo se ha optado por retomar este uso generalizado (el mismo Fallis, aceptó el consenso y se inclinó por respetar la propuesta floridiana). En este sentido, para el caso de la desinformación (la información falsa que se utiliza para engañar), el abordaje académico que generalmente se ha hecho está circunscrito al discurso ético (ya que atañe, principalmente, a los fines e intenciones de las personas), mientras que la malinformación (aquella información falsa que se cree verdadera y se transmite según esa condición) puede recurrir a múltiples perspectivas. Esta distinción es relevante, pues, para el caso de la información que circula con la etiqueta de la veracidad, sin serlo en realidad, la bibliotecología puede y debe intervenir, tanto en la teoría como en la práctica, con el diseño de políticas y servicios para examinar y disipar la difusión de dicha información falsa.

La malinformación suele ser más dañina y difícil de contrarrestar, a diferencia de la desinformación, pues se propaga de una forma similar a como ocurre con fenómenos epidemiológicos, tal y como se da con la viralización. En el control de enfermedades, por ejemplo, muchos de los contagios de cuadros estacionarios se producen de manera inadvertida, cuando las personas no están conscientes de que son portadoras de algún virus (tal vez porque no presentan síntomas); de un modo semejante, la información falsa, que se cree es verdadera, es trasmitida por las personas con mayor facilidad y sin muchas reservas (con mayor confianza y soltura) cuando se 
desconoce que ésta carece de veracidad, puesto que se arraiga fuertemente por diversos motivos. Las personas no saben que están propagando información falsa. Es en este sentido que se afirma que la malinformación puede llegar a ser virulenta y, por consecuencia, mucho más dañina y perniciosa que la desinformación, pero no por cuestiones morales vinculadas al “mal”. Fallis señaló que: "Cuando las personas son conducidas a un engaño tratándose de temas importantes, como oportunidades de inversión, procedimientos médicos o candidatos políticos, esto puede causar daños emocionales, financieros e incluso físicos muy graves” (FALLIS, 2015, p. 402).

Quizá pueda pensarse que la desinformación sigue siendo más dañina que la malinformación, dada esa propensión al engaño alevoso, que es el principal elemento que la define. Esta percepción se llega a afianzar con algunos ejemplos, como cuando las autoridades de un gobierno prodigan información falsa, intencionalmente, acerca de la tasa de crecimiento anual del producto interno bruto, pudiera pensarse que esto es más nocivo, porque nos afecta a todos. Sin embargo, cuando se revela información de carácter oficial — cuantimás en materia económica-, casi siempre existe un dejo de reticencia popular al aceptarla, lo que hace que se le cuestione (finalmente, lo que afecta a las personas es la repercusión del hecho en sí, y no tanto la información acerca de él). Por esta razón, se afirma que la malinformación es más dañina y nociva, porque no suele tener esa natural y espontánea resistencia a creerla. Por lo contrario, se llega a arraigar con fuerza, pues actúa sobre prejuicios cultuales, referentes reconocibles y cuestiones emocionales, lo que hace que las personas abracen esa información, la crean y la difundan. En primer lugar, esa información suele estar bien formulada, al menos sintácticamente, pese a que su contenido semántico no sea verdadero. Además, los elementos emotivos que envuelven a esta información hacen difícil que la gente advierta la falsedad (así como los individuos que no presentan síntomas de un cuadro patológico asumen que no están enfermas).

No todos los documentos aportan información de manera directa, y esto no los hace falsos, pues algunos siguen ofreciendo datos de forma indirecta, asociativa o referencial. Es cierto que en algunas áreas como la medicina genómica, la biotecnología o las nanociencias, la información documental tiende con rapidez a la obsolescencia; pero en otras, como ocurre en la filosofía, la historiografía o la literatura dramática, las obras pueden volverse perennes y un referente en su campo por mucho tiempo. La evolución y estudio de las disciplinas obedece a dinámicas múltiples y complejas, lo mismo la diversidad de las necesidades de información. 
Se necesita mejorar la comprensión de la naturaleza y el alcance de la malinformación, y lo que motiva su proliferación (como los referentes culturales o las cuestiones emotivas), así como los entornos en los que se reproduce:

Las bibliotecas y otros servicios de información están a la vanguardia de los esfuerzos para garantizar que las personas tengan acceso a información de calidad. Ya sea que se deba a un franco error, a la negligencia, a algún prejuicio inconsciente (como en el caso de la malinformación) o un engaño intencional (desinformación), la información incorrecta puede llevar por un mal camino a las personas" (FALLIS, 2015, p. 402).

Como una acotación, es importante puntualizar que la información potencialmente falsa no es necesariamente desechable; la información registrada, en diferentes soportes, entrama los significados de varias formas lógicas y gramaticales, por lo que, falsa o no, sigue conteniendo datos con sentido (o metainformación, si se quiere), por lo que la información falsa también es, desde cierto punto, semántica. A continuación se exponen algunos preceptos sobre la naturaleza de la información falsa, establecidos por Floridi (2005):

- La información falsa puede incluir información auténtica.

- La información falsa puede conducir a información genuina.

- La información falsa puede seguir poseyendo la cualidad de ser informativa, aunque sólo sea indirectamente.

- La información falsa puede apoyar los procesos de toma de decisiones (en la categoría de información falsa, no está incluido el conocimiento informal, como la heurística, como algunos autores sí lo sugieren).

- La información falsa puede ser, en otro escenario, real y relevante (Floridi considera que aquellos datos significativos que son sólo contingentemente falsos representan un caso diferente, y podrían calificarse como un tipo de información; lo que se dice es que habría menos personas previstas para las cuales esta información sea falsa).

- La acción informar no requiere de la verdad, y la información no tiene porqué ser cierta, pero la "malinformación” sí requiere de la mentira, así que debe ser falsa (en medio de un debate electoral, alguien podría interrumpir súbitamente para tomar la palabra y decir "el lunes 4 de abril de 1938 amaneció nublado". Esta puede ser una oración verdadera y verificable, pero está en cuestión si realmente esa información es oportuna y pertinente para la discusión). 
- Si la información falsa no cuenta como información, entonces ¿qué es? Sigue siendo información, pero con otro sentido semántico.

Una respuesta plausible para este último cuestionamiento es que la información falsa todavía es información, es decir, puede ser percibida aún como un cúmulo de datos que conforma contenido semántico. La información falsa continúa informando, aunque se de manera errónea. Posee aún la cualidad de la informatividad (aún puede «informar»), además de cohesión, coherencia, intencionalidad, situacionalidad, entre otros criterios. En otras palabras, la información falsa sigue siendo información, en sentido estricto, pero con un sentido semántico diferente.

\section{Un fondo común de información}

La idea de un fondo común de información surge, principalmente, de la existencia de injusticias hermenéuticas, es decir, por la carencia de recursos hermenéuticos colectivos. El papel de las bibliotecas y archivos es de suma importancia en la idea de la construcción de lo que Fricker denominó "fondo común de información". La información relevante y auténtica debe ser acumulada para que sea usada colectivamente, lo que conlleva que las personas discriminen de quién obtienen esa información, o sea, quiénes son informantes fiables y quiénes no lo son. Para Fricker, "poner en común información promueve un ethos específicamente cooperativo" (FRICKER, 2017, p. 215). Un criterio para demostrar la fiabilidad de un fondo común de información son las denominadas propiedades orientadoras, que son aquellas que ostentan las entidades sociales con "un buen historial de hacer bien este tipo de cosas", es decir, compartir el conocimiento y distinguir entre la información auténtica y la falsa en una sociedad real institucionalizada (FRICKER, 2017, p. 190). El principal cometido de este fondo común de información es el de llevar al mínimo la propensión innata de los seres humanos de sacar ventaja a partir del engaño y el ocultamiento de información (asimetrías informativas), y reducir las disfunciones epistémicas (como los prejuicios de credibilidad) entre los usuarios (sujetos de conocimientos o razonadores prácticos), y basar el proceso de compartir y proporcionar información en relaciones de confianza. Estas relaciones no necesariamente son siempre inclusivas, sino que pueden ser también exclusivas (en el mismo sentido de los procesos de inclusión y exclusión de información de Amartya Sen). A partir de la reflexión de Giulio Adinolfi, un régimen 
comunitarista coadyuva en la conformación de una autodeterminación informativa, y ésta, a su vez, promueve el principio de legalidad, pero sobre todo el principio de lealtad (ADINOLFI, 2007, p. 8-10).

Un fondo común de información estaría integrado por informantes y fuentes de información: "los informantes son agentes epistémicos que transmiten información, mientras que las fuentes de información son estados de cosas a partir de los cuales el investigador puede encontrarse en una posición de recoger información [...] mientras que solo los objetos pueden ser fuentes de información, las personas pueden ser informantes (como cuando alguien refiere algo que queremos saber) o fuentes de información (como cuando el hecho de que nuestro invitado llegue empapado y sacudiendo el paraguas nos permite inferir que llueve)" (FRICKER, 2017, p. 215). Un ejemplo de fuentes de información son las bibliotecas y los archivos, entre otros sistemas de información documental, y para que exista este fondo común de información se requieren agentes informantes (en este caso, bibliotecarios y archivistas) los cuales pueden ser aquellos que "tal vez ocupen una mejor posición para detectar las propiedades relevantes que permitan obtener la fiabilidad necesaria o quizá conozcan mejor qué propiedades son un correlato más pertinente de dicha fiabilidad" (FRICKER, 2017, p. 233).

Paradójicamente, la existencia de un fondo común de información podría resultar en una injusticia epistémica hermenéutica, ya que hipotéticamente se limitaría el criterio autónomo de los individuos en favor del criterio y experticia de este fondo informativo. No obstante, aunque existan vínculos de confianza, eso no elimina la capacidad interpretativa de las personas, ya que pueden surgir elementos y circunstancias extraordinarias que gesten razones para que el sujeto epistémico dude la fiabilidad de sus pautas de confianza, por lo que se puede desprender las presuposiciones a favor de la aceptación: "Está demostrado que más información no conduce de manera necesaria a mejores decisiones. La intuición, por ejemplo, va más allá de la información disponible y sigue su propia lógica. Hoy se atrofia la facultad superior de juzgar a causa de la creciente y pululante masa de información" (HAN, 2016b, p. 17). Contar con información fragmentada implica un injusticia hermenéutica, pero no una incapacidad total para interpretar: "Tener información incompleta, nuestra condición real, está lejos de ser total ignorancia [...] La ignorancia no impone necesidad; no nos conduce en ninguna dirección” (SHKLAR, 2013, p. 132) 
Como se mencionó anteriormente, El principal cometido de este fondo común de información es el de llevar al mínimo la propensión innata de los seres humanos de sacar ventaja a partir del engaño y el ocultamiento de información (asimetrías informativas), y reducir las disfunciones epistémicas (como los prejuicios de credibilidad) entre los usuarios (sujetos de conocimientos o razonadores prácticos), y basar el proceso de compartir y proporcionar información en relaciones de confianza. A pesar de que en el fondo común de información se desenvuelve el acto informativo a través de la relación entre el buen informante (bibliotecario), la fuente de información (la biblioteca o el archivo) y el sujeto de conocimiento (usuario), debe señalarse que las formas de conocimiento son, en última instancia, interpretativas, y dependen siempre de las experiencias y horizontes culturales de los usuarios de cada grupo social.

\section{Consideraciones finales}

La conceptuación más notable de la información reconoce su papel fundamental como fuerza constitutiva en la sociedad. La información como poder potencial no sólo incrementa las capacidades cognoscitivas de los individuos, sino el grado de autonomía de las personas. Este poder potencial se vuelve real a través de prácticas específicas, muchas de las cuales involucran la creación, el procesamiento, los flujos y el uso de la información (los sistemas de información son también vías circulación pero también de canales de resignificación cultural).

El derecho a la información se constituye como el elemento que permitiría establecer condiciones de igualdad y de respeto en un entorno multicultural que se ve inmerso, cada vez más, en el régimen de la globalización. Éste debe avanzar a la par que el desarrollo de la sociedad informacional en su relación con las TIC en las cuales se apoya materialmente. Las condiciones de igualdad no sólo se deben considerar para los procesos de toma de decisiones, sino para fortalecer la participación integral y para el desarrollo de los planes de vida de las personas. El papel de los bibliotecarios y archivistas debe abocarse al abatimiento de las injusticias epistémicas (testimoniales y hermenéuticas), por lo que tendrían que desempeñar su ejercicio profesional "bajo condiciones que hicieran posible que los miembros más desposeídos de la sociedad hablasen sin miedo y con la información adecuada" (SHKLAR, 2013, p. 184). 
Las injusticias informativas no se producen únicamente cuando los otros poseen un horizonte hermenéutico desemejante, sino cuando se les niega a las personas información relevante para su comprensión del mundo. Es gracias a sistemas mediadores de información que se pueden obtener los elementos cognitivos necesarios para entender, contextualizar y evaluar, a través de un proceso de decisión efectivo, la ocurrencia de algún evento en cuestión o las contingencias emergentes del entorno. Cuando se niega información, se suscitan cortocircuitos que se agravan cuando se realizan ajustes arbitrarios e imposiciones en la dinámica de los flujos informativos. También se suscitan estas perturbaciones en la comunicación cuando la información es falsa o cuando se marginalizan a algunos individuos por su condición social, de acuerdo a esquemas hegemónicos determinados. Un ejemplo de este tipo de injusticia en la sociedad de la información es el denominado efecto Mateo, el cual, ante las posibilidades de producción y difusión de información que ofrecen las tecnologías digitales, se generan y se acentúan, al mismo tiempo, brechas cognoscitivas.

\section{Referencias}

BARRY, Brian. Culture and equality: an egalitarian critique of multiculturalism. Cambridge, Massachusetts: Harvard University Press, 2001.

BARRY, Brian. Why social justice matters. Cambridge: Polity, 2005.

BLOKLAND, Hans T. Pluralism, democracy and political knowledge: Robert A. Dahl and his critics on modern politics. Surrey, Inglaterra: Ashgate, 2011.

COOLEY, Thomas F.; NAM, Kwanghee. Asymmetric information, financial intermediation, and business cycles. Economic Theory, [s.l.] , v. 12, n. 3, p. 599-620, out./dez. 1998.

CORRIGAN, Ray. Digital decision making: Back to the future. Heidelberg: Springer, 2007.

FALLIS, Don. Floridi on disinformation. Etica \& Politica: Rivista de Filosofia, Trieste, v. 13, n. 2, p. 201-214, jul./dez. 2011.

FALLIS, Don. What is disinformation? Library Trends, [s.l.], v. 63, n. 3, p. 401-426, dez./fev. 2015.

FLORIDI, Luciano. Is semantic information meaningful data? Philosophy and Phenomenological Research, [s.l.], v. 70, n. 2, p. 351-370, mar./abr. 2005. 
FLORIDI, Luciano. Pasos a seguir para la filosofía de la información. Revista Interamericana de Bibliotecología, Medellín, v. 35, n. 2, p. 213-218, jul./dez. 2012.

FOUCAULT, Michel. El discurso del poder. México: Folios, 1983.

FRASER, Nancy. Escalas de justicia. Barcelona: Herder, 2008.

FRICKER, Miranda. Injusticia epistémica: el poder y la ética del conocimiento. Barcelona: Herder, 2017.

GONZÁLEZ, Fernando. El maestro de escuela. Medellín: Fondo Editorial Universidad EAFIT: Corporación Otraparte, 2015.

GONZÁLEZ DE REQUENA FARRÉ, Juan Antonio. La injustica epistémica y la injusticia del testimonio. Discusiones Filosóficas, Manizales, v. 16, n. 26, p. 49-67, maio/ago. 2015.

HAN, Byung-Chul. El aroma del tiempo: un ensayo filosófico sobre el arte de demorarse. Barcelona: Herder, 2016a.

HAN, Byung-Chul. La expulsión de lo distinto: percepción y comunicación en la sociedad actual. Barcelona: Herder, 2017.

HAN, Byung-Chul. La sociedad de la transparencia. Barcelona: Herder, $2016 \mathrm{~b}$.

LUCAS GAlLEGO, Gonzalo. Parrhesia e injusticias epistémicas. Bajo Palabra: Revista de Filosofía, Madri, n. 17, p. 309-328, 2017.

MARWALA, Tshilidzi; HURWITZ, Evan. Artificial intelligence and economic theory: Skynet in the market. Cham: Springer, 2017.

RAWLS, John. Teoría de la justicia. México: Fondo de Cultura Económica, 2014.

RESTREPO, Luis Carlos. El derecho a la ternura. Bogotá: Arango, 1994.

SEN, Amartya K. Desarrollo y libertad. Bogotá: Planeta, 2010a.

SEN, Amartya K. La idea de justicia. México: Taurus, 2010 b.

SHKLAR, Judith N. Los rostros de la injusticia. Barcelona: Herder, 2013.

WILLIAMS, Bernard. La filosofía como una disciplina humanística. México: Fondo de Cultura Económica, 2017. 